\title{
A Planning Experimental Investigation on Tobacco Leaves Dryer Using Paddy Husk and Coal
}

\author{
Huy- Bich Nguyen ${ }^{\#}$, Hay Nguyen ${ }^{\#}$, Quang Giang Le ${ }^{\#}$ \\ \# Faculty of Engineering and Technology, Nong Lam University Ho Chi Minh city, Viet Nam \\ E-mail:nhbich@hcmuaf.edu.vn,nguyenhay@gmail.com,lqgiang@hcmuaf.edu.vn
}

*National Key laboratory for Digital Control and System Engineering, Viet Nam National University Ho Chi Minh city, Viet Nam

\begin{abstract}
In Viet Nam, the drying technology and techniques for tobacco leaves is one of the most difficulties and plays as key point to get high economic efficiency in tobacco production. To drying for tobacco leaves of 3,500 hectare, for example in Gia Lai province, there needs about 3000 dryers and there is more than 100,000 cubic meter of wood have been burned for drying which equivalent to more than 300 hectare of forest is deforested annually. A designing and manufacturing study for new tobacco dryer to replace the wood fuel by paddy-husk or coal-wood has been implemented. The results indicate that the new dryer using rice-husk or coal can be replaced for the actual drying system used fire wood with the high quality of tobacco leaves and high efficiency. The planning experimental investigation has found the function of the rate of energy consumption and the quality of drying products successful
\end{abstract}

Keywords - Drying engineering, tobacco, paddy husk, fire-wood, coal.

\section{INTRODUCTION}

Tobacco-plant is one of the suitable plants in tropical area and has planted in many developing countries due to its high economy efficiency. It plays as main plant which contributes to increase the jobs, to improve the farmer's income, and to give the rural substainable development. In Viet Nam the development strategy for tobacco production up to year 2020 [1] have show that the area of tobacco plants could be 40,000 hectares with the yield is about 80,000 tonnes of leaf. This leads to the fact that the number of dryer neets at least 30,000 for leaves drying. At present, most of dryer using wood from forest as the main fuel for drying and it might lead to many bad outcomes in terms of environment protection and substainable energy. For example in Gia Lai province, with more than 3,500 hectare of tobacco, there is more than 100,000 cubic meter of wood have been burned for drying which equivalent to more than 300 hecta of forest is deforested annually [2]. Furthermore, it seems to be true that the drying technology and techniques for tobacco leafs in tobacco producing is one of the most difficulties and plays as key point to get high economic efficiency $[3,4]$. Therefore, a designing and manufacturing study for new tobacco dryer to replace the wood fuel by paddy-husk or coal-wood and to improve the drying efficiency are highly requirement and very interesting. This paper presents the results of planning experimental investigation basing on the new leaves tobacco dryer has been developed.

\section{Methods And MATERIAL}

The experimental examination has been set up base on the method of CRD (Completely Randomized Design) [5]. The planning empirical investigation (PEI) is conducted as follow the steps of this method including [6]:

- Selecting the parameters used for experimental investigation.

- Developing the empirical planning with the second order and nonlinearly PEI

- Processing experimental datas and checking the PEI model :

- Applying the variance analysis methods (ANOVA).

- Applying the dispose of coarse error methods from Aknazarova

- Using the Statgraphics-vers 7.0 software to recheck the model base on Fisher standard.

- Finding out the extrema function of the optimixation problems.

The PEI is implemented by using the dryer with two thermal convection systems as shown in figure 1 . The results from this system then are compare with the one using one thermal convection system. 


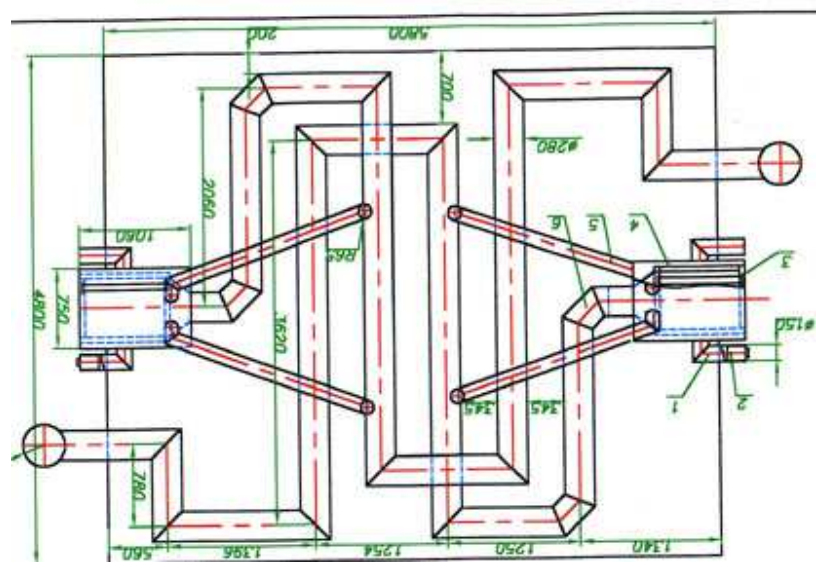

Fig. 1 The dryer with two thermal convection systems

Some characteristic parameters of the dryer and burner (Fig. 2) are:

- Dimension of burner (Length x Wide) : $1 \mathrm{~m}$ x 0,6 m.

- Burner volume: 0,441 m3.

- Material of burner is ceramic block has thickness is 20 $\mathrm{cm}$

- Length of heat exchanger (exchanger pipes): 19,7 m.

- Height of chimmey: $5 \mathrm{~m}$.
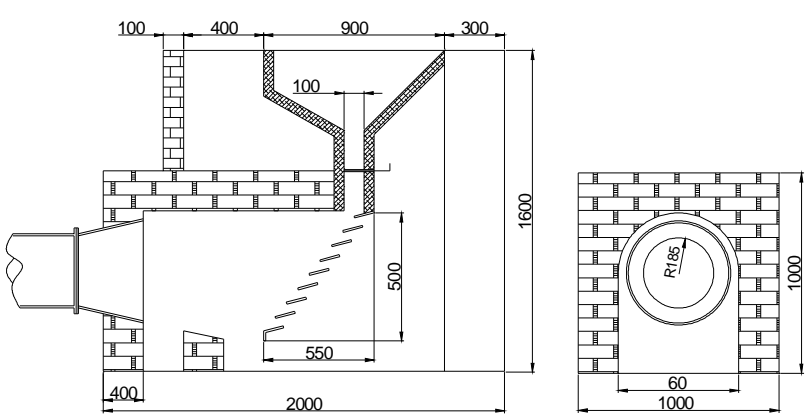

Fig. 2 Burner using paddy husk

\section{RESULTS AND DISCCUSION}

\section{A. Studying PEI to find out the function}

To find out the function, the study has been done with the experimental study factors are the number of floor inside the dryer ( $\mathrm{N}$ (floor)) ; the title angle of heat exchanger ( $\mathrm{G}$ (degree)); the time interval for supplying fuel (T (minutes)) ; and the size of exhaust (S (m2)). The output parameters are the product quality $(\mathrm{L}(\%))$ and the rate of fuel per one unit of product $\mathrm{Ar}$ ( $\mathrm{kg} / \mathrm{kg}$ dried tobacco leaves). The experimental investigation is conducted with variation and empirical level as shown in table 1 .

TABLE I

The LeVel And Variation Of The EXPERIMENTAL FaCtors For Pei

\begin{tabular}{|c|c|c|c|c|c|c|}
\hline \multirow{2}{*}{ Factors } & \multicolumn{5}{|c|}{ level } & \multirow{2}{*}{ Variation } \\
\cline { 2 - 6 } & +1 & 0 & -1 & $+\alpha$ & $-\alpha$ & \\
\hline $\mathrm{N}$ & 6 & 5 & 4 & 7 & 3 & 1 \\
\hline $\mathrm{G}$ & 4 & 3 & 2 & 5 & 1 & 1 \\
\hline $\mathrm{T}$ & 110 & 100 & 90 & 120 & 80 & 10 \\
\hline $\mathrm{S}$ & 1,8 & 1,6 & 1,4 & 2,0 & 1,2 & 0,2 \\
\hline
\end{tabular}

The function of the rate of fuel per one unit of product Ar from PEI study is:

$\mathrm{Ar}=32,23334-12,07680 . \mathrm{N}+3,20386 . \mathrm{G}-1,25417(\mathrm{E}-3) \mathrm{T}+$ $2,74323 . \mathrm{S}+0,0132687 . \mathrm{NT}-0,0265063 . \mathrm{GT}-0,484062 . \mathrm{GS}$ $+0,953537 . \mathrm{N} 2+0,116537 . \mathrm{G} 2$

and the function of the product quality $\mathrm{L}$ is:

$\mathrm{L}=-127,245+12,3828 . \mathrm{N}+0,153244 . \mathrm{G}+1,74362 . \mathrm{T}+$ 78,5707.S + 0,103313.NT + 4,30313.GS - 2,40353.N2 + $0,937277 . \mathrm{N} 2-0,0121613 . \mathrm{T} 2-25,2757 . \mathrm{S} 2$
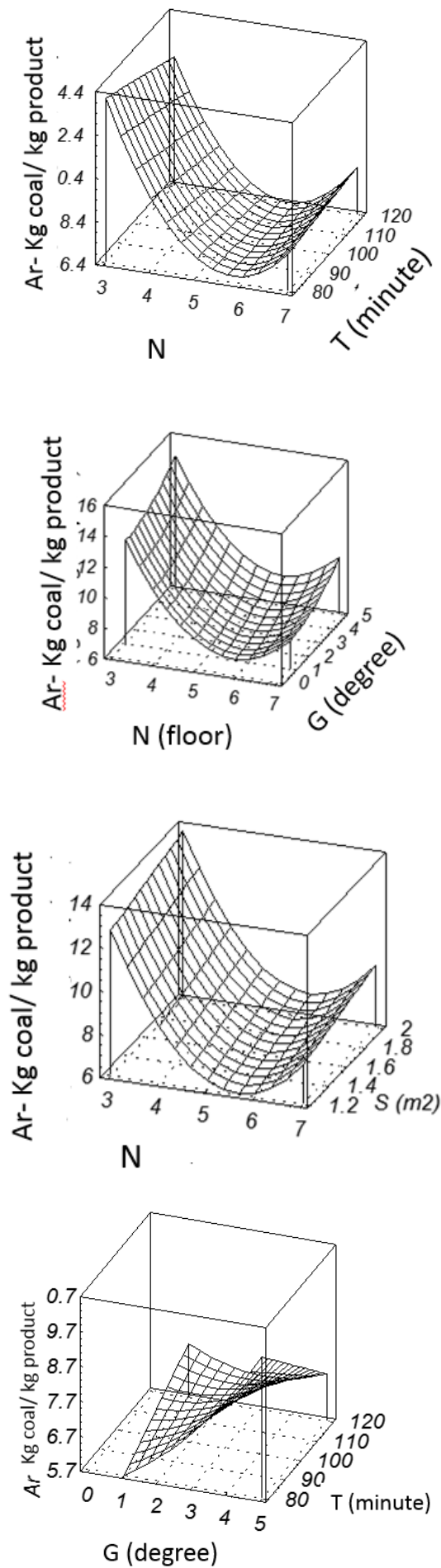


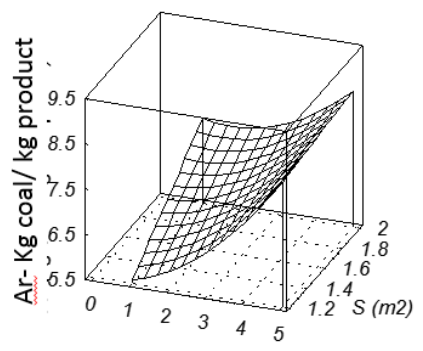

G (degree)

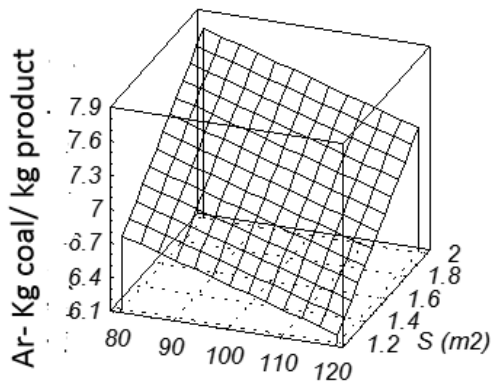

$\mathrm{T}$ (minute)

Fig. 3 The graph of relationship between two factors of dryer and the rate of fuel consumption $A_{r}$
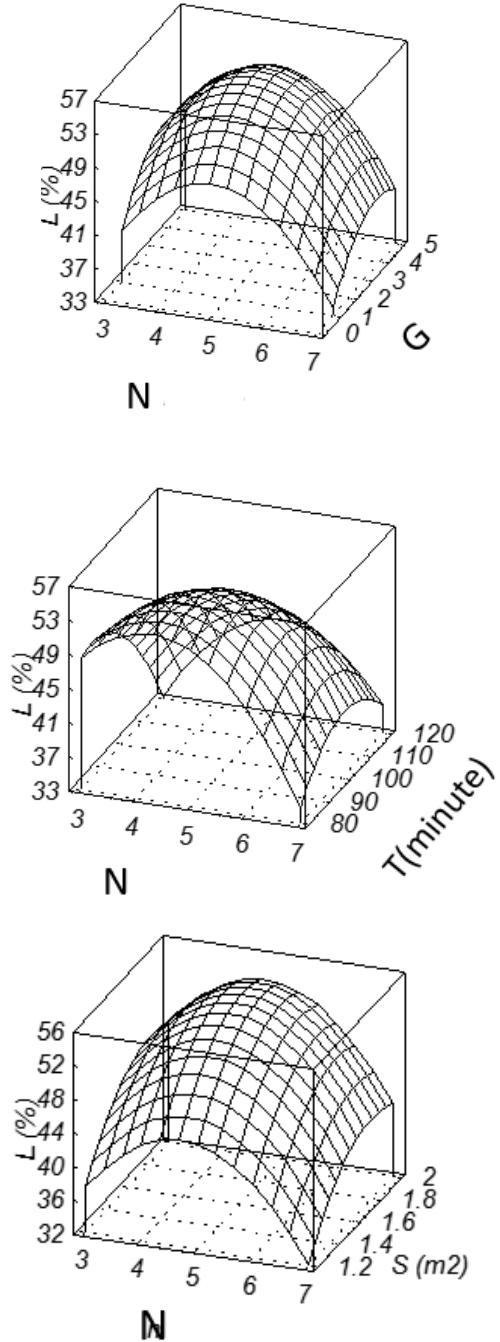
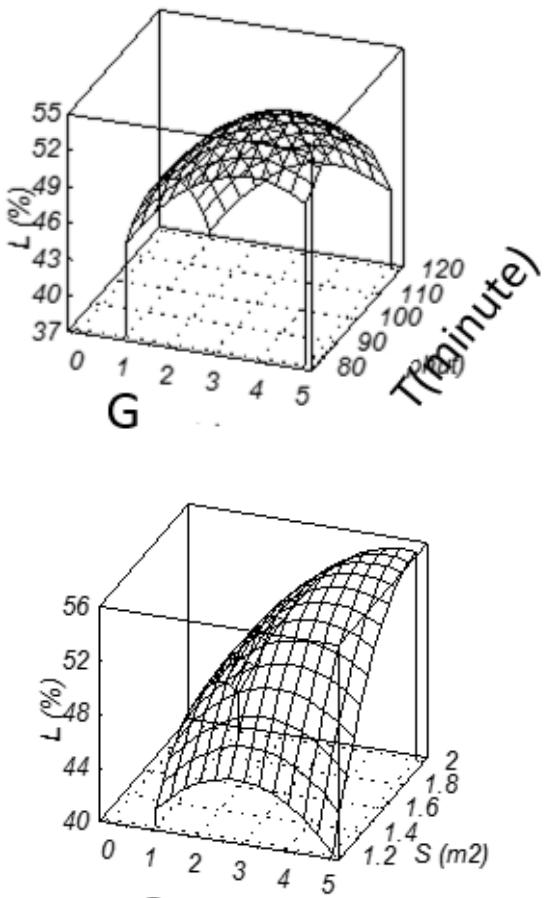

G

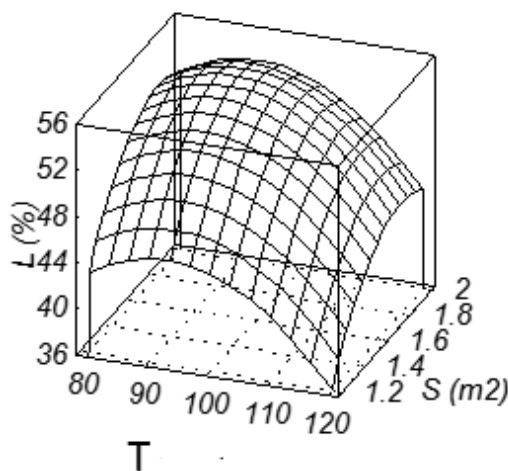

Fig. 4 The graph of relationship between two factors of dryer and the quality of product $\mathrm{L}$

The relationship and effect of two factor as the title angle of heat exchanger $\mathrm{G}$ and the time interval for supplying fuel $\mathrm{T}$ on the rate of fuel per one unit of product $\mathrm{Ar}$ and the product quality $\mathrm{L}$ is presented in Fig.3 and Fig.4, respectively.

From these results, it shown that the function of Ar leads to minimum magnitude as Armin $=5,9 \mathrm{~kg}$ coal per $\mathrm{kg}$ of product and the one of $\mathrm{L}$ pass to maximum value as $\mathrm{Lmax}=$ $56,64 \%$ with the factors of dryer satisfied as follow: $\mathrm{N}=5$ floor; $\mathrm{G}=3$ degree 6 minutes; $\mathrm{T}=97$ minutes; and $\mathrm{S}=1.64$ $\mathrm{m} 2$.

B. Experimental test results for dryer using coal and paddy husk:

The experimental investigation for fuel consumption using coal and paddy husky is presented in table 2 . It can be seen that the average fuel consumption using coal and paddy husk for tobacco drying is $2214 \mathrm{~kg} / \mathrm{batch}$ and $3272 \mathrm{~kg} / \mathrm{batch}$ with productivity is $587 \mathrm{~kg} / \mathrm{batch}$ and $536 \mathrm{~kg} / \mathrm{batch}$, respectively. The price of coal and paddy husk is $2500 \mathrm{VND}$ and 900 VND or 0.12 USD and 0.04 USD for one kilogram, respectively. Therefore, it might count that the fuel price to 
drying one kilogram tobacco is 0.445 USD and 0.259 USD when use coal and paddy husk, respectively. It might see that there is a huge different in energy burned for drying between two kind of fuel. It can conclude that using paddy husk is best choice for tobacco drying which leads to save more than $41 \%$ of energy consumption and especially saving our environment.

\section{TABLE III}

The Rate Of Fuel Consumption Per One Unit Of Product Ar

\begin{tabular}{|c|c|c|c|c|}
\hline \multirow{2}{*}{ No } & \multicolumn{2}{|c|}{ Coal dryer } & \multicolumn{2}{c|}{ Paddy husk dryer } \\
\cline { 2 - 5 } & $\begin{array}{c}\text { Coal } \\
\text { consumption } \\
\text { per batch } \\
(\mathrm{kg})\end{array}$ & $\begin{array}{c}\text { Dried } \\
\text { Tobacco per } \\
\text { batch }(\mathrm{kg})\end{array}$ & $\begin{array}{l}\text { Paddy husk } \\
\text { consumptio } \\
\text { n per batch } \\
(\mathrm{kg})\end{array}$ & $\begin{array}{l}\text { Dried } \\
\text { Tobacco } \\
\text { per batch } \\
(\mathrm{kg})\end{array}$ \\
\hline $\mathbf{1}$ & 2110 & 546 & 3215 & 530 \\
\hline $\mathbf{2}$ & 2215 & 577 & 3250 & 540 \\
\hline $\mathbf{3}$ & 2012 & 529 & 3210 & 534 \\
\hline $\mathbf{4}$ & 2340 & 641 & 3306 & 562 \\
\hline $\mathbf{5}$ & 2305 & 629 & 3290 & 535 \\
\hline $\mathbf{6}$ & 2284 & 616 & 3312 & 558 \\
\hline $\mathbf{7}$ & 2256 & 585 & 3285 & 516 \\
\hline $\mathbf{8}$ & 2140 & 555 & 3285 & 520 \\
\hline $\mathbf{9}$ & 2262 & 601 & 3296 & 527 \\
\hline Average & $\mathbf{2 2 1 4}$ & $\mathbf{5 8 7}$ & $\mathbf{3 2 7 2}$ & $\mathbf{5 3 6}$ \\
\hline
\end{tabular}

The quality of dried product also is investigated. The results of classification for tobacco leaves is shown in Table 3. The code class is from 1 to 4 which means from excellent to normal.

\section{TABLE IIIII}

The Rate Of Fuel Consumption Per One Unit Of Product AR

\begin{tabular}{|c|c|l|l|l|l|l|l|l|}
\hline \multirow{2}{*}{ No } & \multicolumn{3}{|c|}{$\begin{array}{c}\text { Dried tobacco quality (\%) } \\
\text { using Coal dryer }\end{array}$} & \multicolumn{4}{c|}{$\begin{array}{c}\text { Dried tobacco quality } \\
\text { using paddy husk dryer }\end{array}$} \\
\cline { 2 - 9 } & $\begin{array}{l}\text { class } \\
\text { one }\end{array}$ & $\begin{array}{l}\text { class } \\
\text { two }\end{array}$ & $\begin{array}{l}\text { class } \\
\text { three }\end{array}$ & $\begin{array}{l}\text { class } \\
\text { four }\end{array}$ & $\begin{array}{l}\text { class } \\
\text { one }\end{array}$ & $\begin{array}{l}\text { class } \\
\text { two }\end{array}$ & $\begin{array}{l}\text { class } \\
\text { three }\end{array}$ & $\begin{array}{l}\text { class } \\
\text { four }\end{array}$ \\
\hline $\mathbf{1}$ & 36.5 & 30.2 & 18.8 & 14.5 & 28.6 & 25.4 & 25.6 & 20.4 \\
\hline $\mathbf{2}$ & 38.2 & 28.3 & 19.7 & 13.8 & 30.6 & 28.3 & 21.4 & 19.7 \\
\hline $\mathbf{3}$ & 40.5 & 29.6 & 17.5 & 12.4 & 32.7 & 26.5 & 22.5 & 18.3 \\
\hline $\mathbf{4}$ & 38.6 & 31.4 & 17.5 & 12.5 & 30.6 & 27.2 & 22.5 & 19.7 \\
\hline $\mathbf{5}$ & 36.4 & 32.8 & 20.6 & 10.2 & 29.5 & 28.4 & 25.2 & 16.9 \\
\hline
\end{tabular}

\begin{tabular}{|c|c|c|c|c|c|c|c|c|}
\hline $\mathbf{6}$ & 37.5 & 30.8 & 22.2 & 9.5 & 33.2 & 24.7 & 24.6 & 17.5 \\
\hline $\mathbf{7}$ & 35.8 & 31.6 & 21.4 & 11.2 & 31.3 & 27.6 & 21.4 & 19.7 \\
\hline $\mathbf{8}$ & 38.2 & 28.6 & 20.8 & 12.4 & 32.6 & 27.4 & 23.5 & 16.5 \\
\hline $\mathbf{9}$ & 39.4 & 29.5 & 18.6 & 12.5 & 31.7 & 26.4 & 26.3 & 15.6 \\
\hline $\begin{array}{c}\text { Av } \\
.\end{array}$ & $\mathbf{3 7 . 9}$ & $\mathbf{3 0 . 3}$ & $\mathbf{1 9 . 7}$ & $\mathbf{1 2 . 1}$ & $\mathbf{3 1 . 2}$ & $\mathbf{2 6 . 9}$ & $\mathbf{2 3 . 7}$ & $\mathbf{1 8 . 3}$ \\
\hline
\end{tabular}

Table 4 indicates that using coal for drying might make the tobacco leaves have higher rate of class one and lower class four comparing the one use paddy husk. This can be explained that the energy unit of coal is always higher than paddy husk so that it is easy to control and adjust the temperature inside the dryer.

\section{CONCLUSIONS}

This study presents the results of using coal and paddy husk for tobacco leaves drying in two heat convection system dryer. It shown that using paddy husk is best choice for tobacco drying which help saving more fuel consumption and our environment. The effect of some factors of dryer on the rate of fuel consumption per one kilogram product and the quality of product has been found. The optimization function of these factors also clearly presents which indicate the minimum and maximum magnitude.

\section{REFERENCES}

[1] Viet Nam government's decree No. 88/2007/QĐ-TTg for the stractegy of tobaccon develop up to year 2020

[2] Nguyen Hay, Nguyen Huy Bich, and Le Quang Giang, 2014, A Study On Tobacco Leaves Dryer With 3 Ton/Batch Capacity Using Paddy Husk And Coal, Viet Nam Journal of Mechanical Engineering. No.8-2014.

[3] Nguyễn Hay,1998, study on natural convection dryer techniques to increase the tobacco leaves quality, $\mathrm{PhD}$ thesis, Nong Lam University Ho Chi Minh city, Viet Nam.

[4] A. Hirun and A. Promwungkwa. Flue Curet Tobacco. Deparment of mechanical Engineering Chiang Mai University, Chiang Mai 50002, Thailand.

[5] Nguyễn Cảnh,1993. Planning experiment. University of Technology Ho Chi Minh city, Viet Nam.

[6] Phan Hiếu Hiền, 2001. The methods of planing experiment and statics processing, Agriculture Publishing House, Viet Nam. 